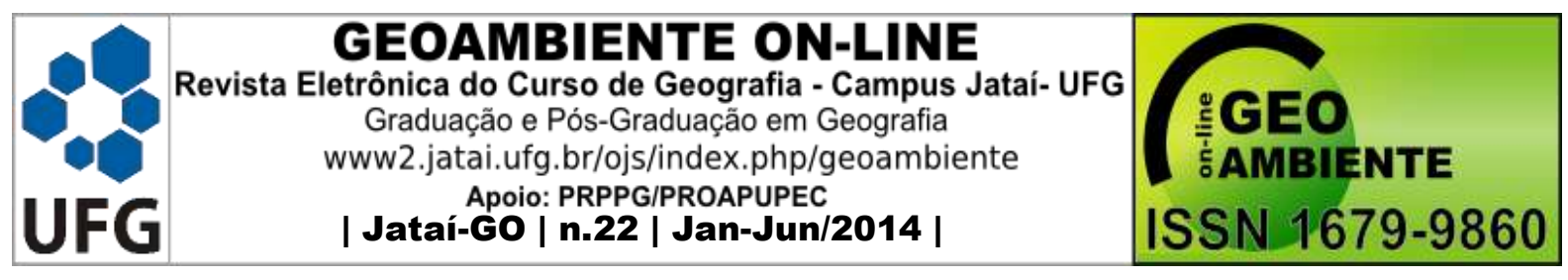

\title{
PRÁTICAS EDUCATIVAS ESTRUTURANTES DO HABITUS DA JUVENTUDE RURAL NO CAMPO DA MODERNIZAÇÃO AGRÍCOLA
}

Cátia Regina Assis Almeida Leal ${ }^{\mathbf{1}}$, Dinalva Donizete Ribeiro ${ }^{2}$

(1 - Universidade Federal de Goiás - Professora da Regional Jataí/UFG, catiaassisleal@gmail.com, 2 - Universidade Federal de Goiás, Professora da Escola de Agronomia/UFG, dinalvadr@gmail.com)

\section{Resumo}

O projeto "Jovens Rurais" propôs práticas educativas que fossem significativas para jovens assentados. Buscou-se possibilidades educativas para resgatar valores da cultura campesina e contribuir na constituição de novos habitus, capazes de configurar nova cultura naqueles jovens. A execução desse projeto gerou tensões quanto às práticas educativas. Por um lado temos a escola rural, na perspectiva do desenvolvimento agrícola exógeno. Por outro, tivemos o projeto "Jovens Rurais" na perspectiva do desenvolvimento agrícola endógeno. Tal tensão suscitou uma pesquisa para avaliar os impactos do projeto para os jovens envolvidos. A metodologia utilizada foi bibliográfica/ documental. A pesquisa revelou que práticas educativas presentes no campo da modernização agrícola influenciam na constituição do habitus da juventude. Mas, pode haver inversão dessa situação, ligada à constituição de novas práticas educativas dos sujeitos históricos. Estas foram percebidas com o projeto, tendo gerado novos habitus. Como referencial de análise, pautou-se na Teoria da Prática de Pierre Bourdieu.

Palavras - chave: Educação; cultura; juventude rural.

\section{Abstract \\ EDUCATIONAL PRACTICES THAT STRUCTURE THE HABITUS OF YOUNG PEOPLE IN THE FIELD OF AGRICULTURAL MODERNIZATION}

The project "Jovens Rurais" has proposed educational practices significant to young from settlements. We tried educational possibilities to rescue the values of peasant culture and to

\footnotetext{
Artigo recebido para publicação em 05 de Fevereiro de 2014

Artigo aprovado para publicação em 05 de Junho de 2014
} 


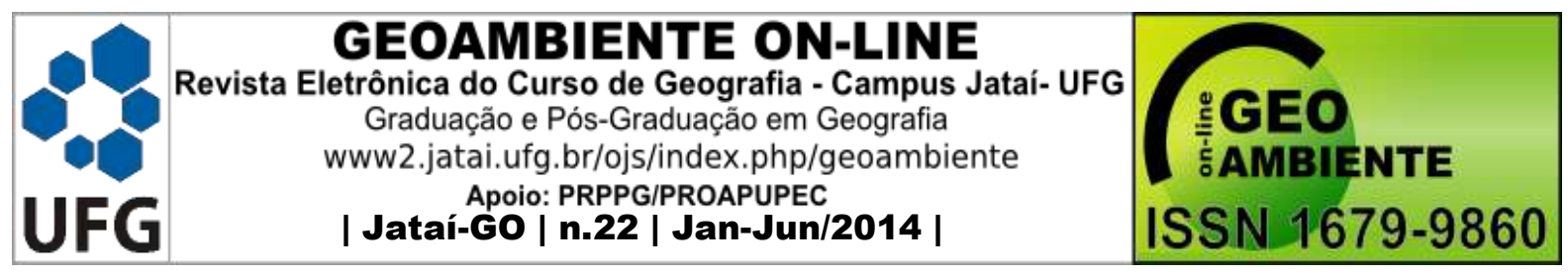

contribute to the formation of new habitus, adequate to configure new culture in youth. The execution of project has generated tensions with regard to educational practices. Rural school about the prospect of exogenous agricultural development and the project with perspectives of endogenous agricultural development. This tension led to a research to assess the impacts of this project in involved youth. The methodology used was bibliographic/documental. The research revealed that these educational practices in the field of agricultural modernization have influenced the constitution of habitus of youth. But this situation can be reversed, linked to the creation of new educational practices of historical subjects. This situation was observed in the project, generating new habitus. To analysis we used the Theory of Practice by Pierre Bourdieu.

Keywords: Education; culture; rural youth.

\section{Resumen}

\section{PRÁCTICAS EDUCATIVAS ESTRUCTURANTES DEL HABITUS DE LA}

\section{JUVENTUD RURAL EN EL CAMPO DE LA MODERNIZACIÓN AGRÍCOLA}

El proyecto "Juventud Rural" ha propuesto prácticas educativas que tienen significado para los jóvenes colonos. Se ha buscado nuevas posibilidades educativas para rescatar los valores culturales del campo y contribuir al establecimiento de nuevos habitus, capaces de configurar una nueva cultura en los jóvenes. La implementación de este proyecto ha generado tensiones con respecto a las prácticas educativas. Por un lado, tenemos la escuela rural en la perspectiva del desarrollo agrícola exógeno. Por otro, tenemos el proyecto de "Jóvenes del Medio Rural" desde la perspectiva del desarrollo agrícola endógeno. Tal tensión es que provocó la realización de una investigación para evaluar los impactos del proyecto para los jóvenes involucrados. La metodología utilizada fue bibliográfica y documental. La investigación reveló que las prácticas educativas actuales en el campo de la modernización agrícola influyen en la constitución del habitus de la juventud. Pero, puede haber inversión de esta situación, vinculada a la formación de nuevas prácticas educativas de los sujetos históricos. Estas fueron percibidas con el proyecto, habiendo generado nuevos habitus. Como referencia para el análisis, hemos fundamentado la investigación en la Teoría de la Práctica de Pierre Bourdieu.

Palabras-clave: Educación; cultura; juventud rural.

\section{Introdução}




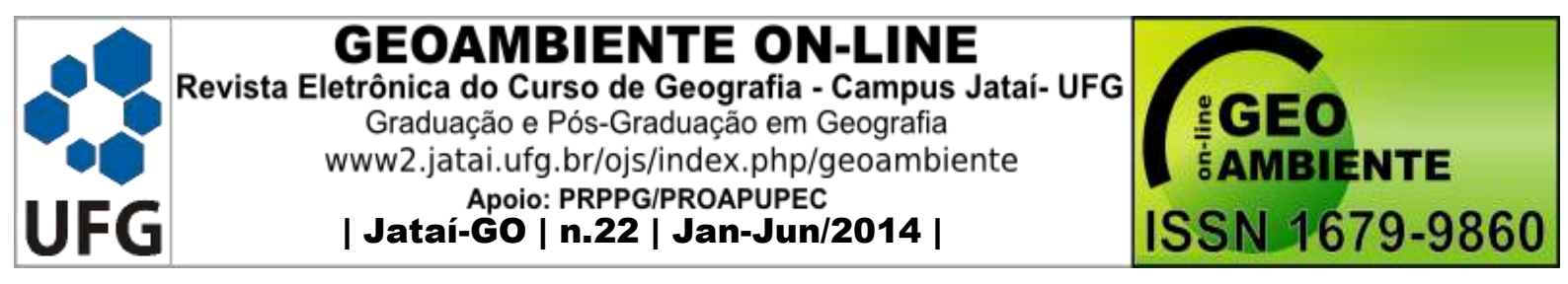

O projeto "Jovens Rurais", submetido ao edital 23/2008 (MCT/CNPq/CTAGRONEGÓCIO/MDA - Programa Intervivência Universitária) teve como principal objetivo atender 60 jovens residentes e estudantes em áreas rurais, assentamentos de reforma agrária, com idade entre 12 e 18 anos que demonstrassem experiência e/ou aptidão para ações educativas, extensionistas e organizativas. O objetivo foi divulgar e socializar conhecimento produzido e sistematizado pelos Centros Especializados ${ }^{1}$ e fornecer subsídios práticos para sua utilização, por meio do envolvimento e da instrumentalização técnica, social e política dos jovens.

Objetivou ainda instrumentalizar os jovens para atuarem como multiplicadores e agentes de desenvolvimento nos seus assentamentos de origem no sentido da transição agroecológica; estimular o desenvolvimento de habilidades e competências nos jovens dandolhes treinamento, orientação e acompanhamento a fim de garantir a aplicabilidade do que for tratado nos módulos de vivência; estimular o espírito de liderança e de coletividade nos jovens rurais, com orientação para a organização sócio-política e o desenvolvimento nos seus assentamentos; revitalizar a identidade e a socialização camponesa e resgatar a percepção de suas condições de herdeiros de uma identidade e de uma terra; estimular os jovens na compreensão do lugar que ocupam, de si mesmos e da sociedade, de seus desejos de mudança e da afirmação como membros de um grupo social.

Para alcançar esses objetivos a execução do projeto materializou-se na forma de vivências universitárias por meio da realização de módulos de estudos. Eles funcionaram como momento e local de interlocução entre os jovens e os profissionais qualificados para os temas abordados, com o acesso dos jovens aos laboratórios, experimentos, bibliotecas, grupo de estudos, projetos, programas, dentre outros espaços e atividades da Universidade Federal de Goiás, Campus Jataí.

As vivências universitárias foram orientadas pelas linhas de apoio previstas no projeto: Organização Social e Associativismo; Ecologia, Legislação Ambiental e Utilização de Recursos Naturais; Produção Agrícola, Zootécnicas e Agroecológica. Essas três linhas de apoio permitiram desenvolver ações junto aos jovens rurais na perspectiva da transição agroecológica tendo como pretensão alcançar níveis de organização, de produção, de

\footnotetext{
${ }^{1}$ Considera-se nesse artigo, como Centro Especializado, o NEAF - Núcleo de Estudos, Pesquisa e Extensão em Agricultura Familiar do Campus Jataí da Universidade Federal de Goiás.
} 


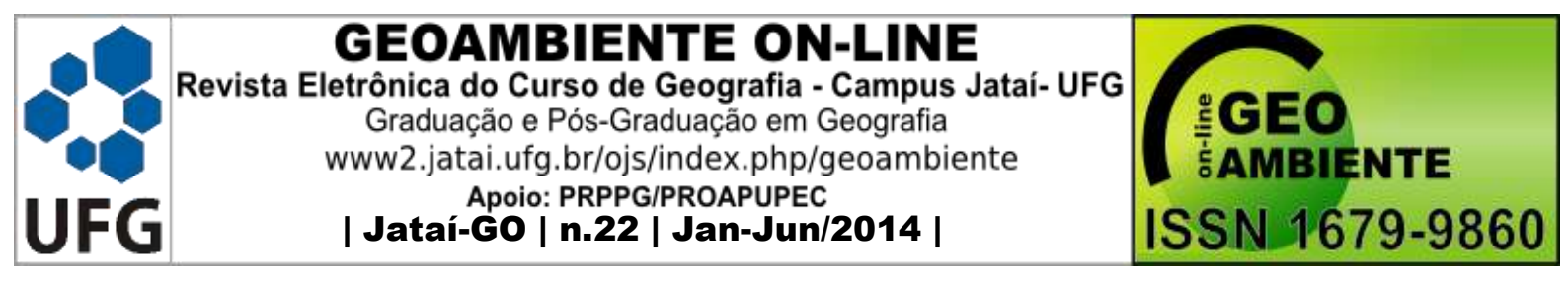

comercialização, de renda e de qualidade ambiental e de vida mais elevados, gerando condições para a autonomia e a sustentabilidade dos assentamentos envolvidos com o projeto.

Nos períodos de intervalos entre uma vivência e outra houve uma atividade de acompanhamento das atividades desenvolvidas pelos jovens em seus assentamentos de origem. Essas atividades foram monitoradas e supervisionadas pela equipe técnica integrante do projeto. O objetivo foi orientar os jovens na execução das ações desenvolvidas por eles a partir dos conhecimentos adquiridos em cada uma das vivências universitárias.

Durante o período de execução do projeto foram ofertados quatro módulos de vivências universitárias, atendendo 60 jovens entre 12 a 18 anos de 4 assentados de reforma agrária dos municípios de Jataí e Perolândia. O projeto foi implementado e desenvolvido em parceria com esses assentamentos e Universidade Federal de Goiás, Campus Jataí e conduzido pelo Núcleo de Estudos, Pesquisa e Extensão em Agricultura Familiar (NEAF) da UFG/CAJ.

Um dos motivadores para o proposição desse projeto de extensão foi a constatação de que, nessa região, as escolas rurais, nos moldes como hoje está constituída, pouco ou nada tem contribuído com os saberes e fazeres necessários aos jovens que vivem no/do campo. (LEAL, 2008)

As escolas rurais dos municípios atendidos pelo projeto surgiram face as necessidades de apreensão de conhecimento relacionados ao processo de modernização agrícola empreendido no país, e na região do Sudoeste Goiano, a partir da década de 1970. Nesse sentido elas seguem construindo práticas educativas constitutivas de habitus capazes de perpetuar um modelo de desenvolvimento que interessa apenas à agricultura/agricultores capitalistas.

Nesse sentido, o projeto "Jovens Rurais", foi pensado e executado com vistas a propor práticas educativas que fossem mais significativas para os jovens que estudam, trabalham e vivem no/do campo. Ou seja, nele procurou desenvolver práticas educativas que fizessem mais sentido e significado para os jovens assentados. Buscou-se possibilidades educativas capazes de resgatar valores da cultura campesina, podendo assim, contribuir para constituição de novos habitus, capazes de configurar nesses jovens uma nova cultura ${ }^{2}$, de maneira a assegurar a constituição, a consolidação, a manutenção, a reprodução e a conformação de um modelo de desenvolvimento endógeno.

\footnotetext{
${ }^{2}$ Nos textos de Bourdieu, a palavra cultura é tomada geralmente em sentido que remete às obras culturais, aos produtos simbólicos socialmente valorizados ligados ao domínio das artes e das letras. Bourdieu trata da cultura recorrendo ao conceito de habitus (Ver CUCHE, 2002).
} 


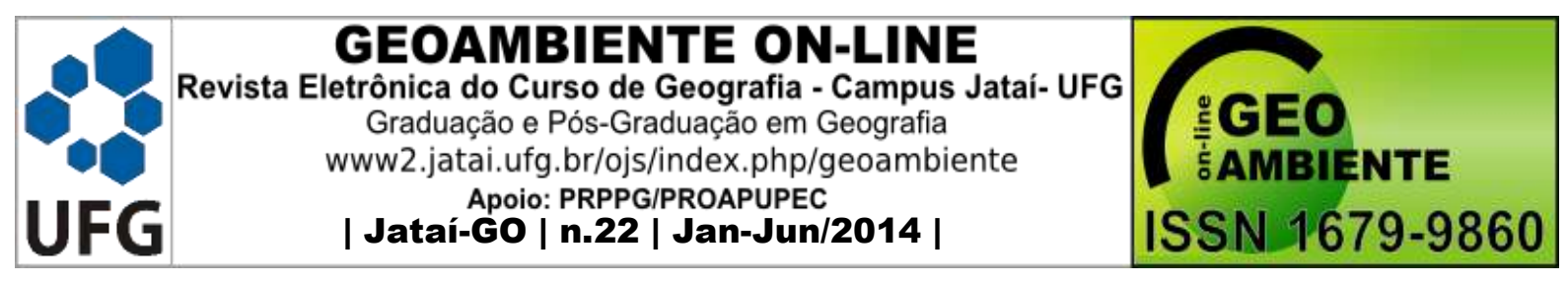

Nota-se que a execução desse projeto de extensão gerou uma tensão no que se refere às práticas educativas. De um lado temos a escola rural que forma na perspectiva de manutenção do status quo, ou seja, de um modelo de desenvolvimento agrícola exógeno. Do outro lado, temos o projeto "Jovens Rurais" que forma na perspectiva de um modelo de desenvolvimento agrícola endógeno.

Partindo dessa tensão gera-se então a necessidade de uma pesquisa que pudesse avaliar os impactos da implantação do projeto "Jovens Rurais", e são os resultados dessa pesquisa que esse artigo pretende apresentar. Para compreender os impactos da implantação desse projeto na vida desses jovens utilizar-se-á como referencial de análise a Teoria da Prática de Pierre Bourdieu. Por isso categorias fundantes utilizadas pelo autor: espaço social, campo, habitus, capital, entre outras, serão apresentadas.

\section{Desenvolvimento}

Para Bourdieu (1998), um instrumento utilizável na busca da compreensão de um objeto de estudo é a formação de um quadro dos caracteres pertinentes de um conjunto de agentes ou de instituições. Esse recurso obriga a pensar relacionalmente, pensar em termos de realidades que podem ser vistas claramente em termos de relações. Para o autor, se é verdade que o real é relacional, pode acontecer que nada se saiba de uma instituição acerca da qual se julga saber tudo, porque ela nada é fora das suas relações com o todo, portanto vale mais estudar extensivamente um conjunto dos elementos pertinentes do objeto construído.

Esse referencial teórico-metodológico utilizado na pesquisa remete a pensar nas relações que se processam entre a sociedade e os atores sociais, na mediação entre o campo e o habitus, ou entre a estrutura e o ator. Para esse autor a apreensão do espaço social se dá de maneira relacional. Para ele,

É preciso, de fato, aplicar o modo de pensar relacional ao espaço social dos produtores: o microcosmo social, no qual se produzem obras culturais, campo literário, campo científico etc., é um espaço de relações objetivas entre posições [...] e não podemos compreender o que ocorre a não ser que situemos cada agente ou cada instituição em suas relações objetivas com todos os outros (BOURDIEU, 1996, p. 60).

Bourdieu trabalha com duas categorias fundantes em seu esquema explicativo: habitus e campo. 


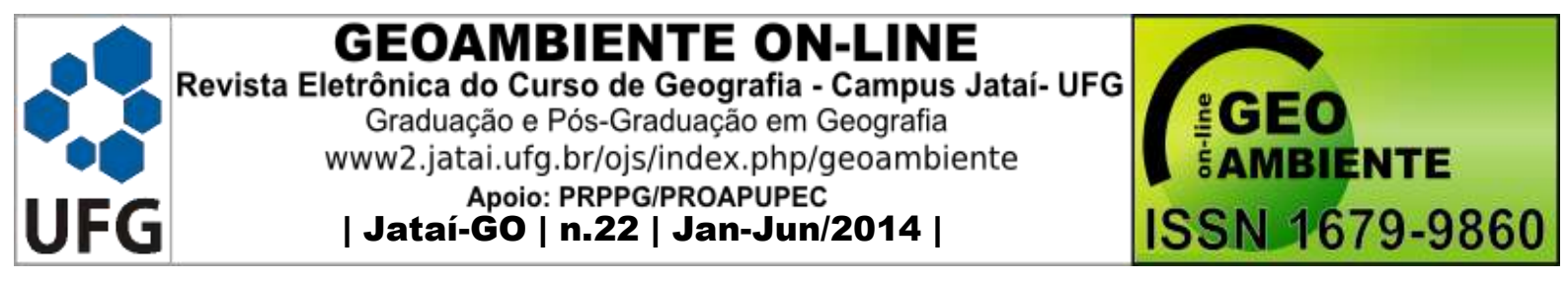

O habitus nada mais é do que essa lei imanente, lex insita, depositada em cada agente pela educação primeira, condição não somente da concertação das práticas mas também das práticas de concertação, posto que as correções e os ajustamentos conscientemente operados pelos próprios agentes supõem o domínio de um código comum e que os empreendimentos de mobilização coletiva não podem ter sucesso sem um mínimo de concordância entre os habitus dos agentes mobilizadores (profetas, chefes de partido, etc.) e as disposições daqueles cujas aspirações eles se esforçam por exprimir (ORTIZ, 2003, p. 64, grifo do autor).

Para Bourdieu, citado por Martins (1987), habitus é um sistema de disposições duráveis. A sua existência resulta de um processo de aprendizado, produto do contato dos agentes sociais com diversas modalidades de estruturas sociais. O habitus adquirido pelo ator social, por meio de sua inserção em diferentes espaços sociais, constitui uma matriz de percepção, de apreciação e de ação que se realiza em determinadas condições sociais. $\mathrm{O}$ habitus informa a conduta, as suas estratégias de conservação e/ou de transformação das estruturas que estão no princípio de sua produção.

Assim, habitus

são sistemas de disposições duráveis e transferíveis, estruturas predispostas a funcionar como estruturas estruturantes, isto é, como princípios geradores e organizadores de práticas e de representações que podem ser objetivamente adaptadas a seu fim sem supor a intenção consciente dos fins e o domínio expresso das operações necessárias para atingi-los, objetivamente "reguladas" e "regulares", sem ser o produto da obediência a regras, sendo coletivamente orquestradas, sem ser o produto da ação organizadora de um regente (MARTINS,1987, p. 40).

O habitus orienta as práticas individuais e coletivas. Ele tende a assegurar a presença ativa das experiências passadas que, depositadas em cada indivíduo sob a forma de esquema de pensamento, percepção e ação, contribui para garantir a conformidade das práticas e de sua constância através do tempo. Por meio do habitus, o passado do indivíduo sobrevive no momento atual, atualizando-se nas práticas realizadas no presente, e tende a subsistir nas ações futuras dos atores sociais ao confrontar com situações conjunturais nos diversos espaços sociais. Ele torna possível a criação de novas modalidades de conduta dos atores sociais.

Se o habitus orienta a prática ${ }^{3}$ dos agentes, esta somente se realiza na medida em que as disposições duráveis dos atores entram em contato com uma situação. Essa situação é denominada em seus trabalhos sobre campo, que é uma outra categoria central em seu esquema explicativo. O campo é um espaço social que possui uma estrutura própria,

\footnotetext{
${ }^{3}$ Prática em Bourdieu é entendida como produto de uma "relação dialética" entre uma situação e um habitus, isto é, o habitus como sistema de disposições duráveis é matriz de percepção, de apreciação e de ação, que se realiza em determinadas condições sociais (MARTINS, 1987).
} 


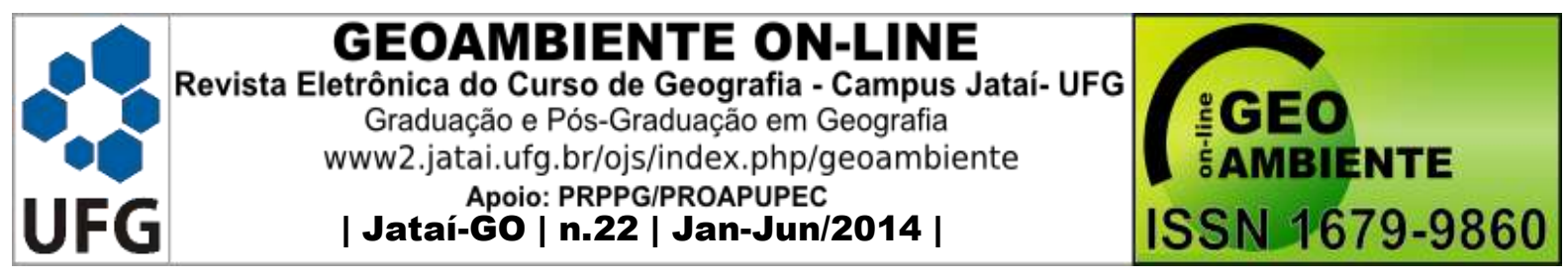

relativamente autônoma em relação a outros espaços sociais, isto é, em relação a outros campos sociais. Mesmo mantendo uma relação entre si, os diversos campos sociais se definem por meio de objetivos específicos, que lhe garantem uma lógica particular de funcionamento e de estruturação. É característico do campo possuir suas disputas e hierarquias internas, assim como princípios que lhe são inerentes cujos conteúdos estruturam as relações que os atores estabelecem entre si no seu interior. A lógica específica de um campo só é compreensível para aqueles que dele participam.

Segundo Bourdieu (1983), um campo

[...] se define entre outras coisas através da definição dos objetos de disputa e dos
interesses específicos que são irredutíveis aos objetos de disputa e aos interesses
próprios de outros campos e que não são percebidos por quem não foi formado para
entrar neste campo (cada categoria de interesses implica na indiferença em relação a
outros interesses, a outros investimentos, destinados assim a serem percebidos como
absurdos, insensatos, ou nobres, desinteressados). Para que um campo funcione, é
preciso que haja objetos de disputa e pessoas prontas para disputar o jogo, dotada de
habitus que impliquem no conhecimento e no reconhecimento das leis imanentes do
jogo, dos objetos de disputa, etc. (p. 89 , grifo do autor).

Para aprofundar no estudo do campo, faz-se necessário compreender a noção de espaço social ${ }^{4}$. Segundo Bourdieu (1996), o espaço é o "conjunto de posições distintas e coexistentes, exteriores umas às outras, definidas umas em relação às outras por uma exterioridade mútua e por relações de proximidade, de vizinhança ou de distanciamento e, também, por relações de ordem" (p. 18-19, grifo do autor).

O campo é um espaço social com estrutura própria relativamente autônoma em relação a outros campos. Os diversos campos sociais mantêm relação entre si, mas são definidos por objetivos específicos que garantem sua lógica particular de funcionamento e estruturação. O campo possui hierarquias e disputas internas que são compreendidas por aqueles que dele participam. Para o funcionamento de um campo é necessária a existência de objetos em disputa e pessoas dotadas de habitus prontas para disputar. A compreensão das categorias habitus e campo é fundamental na medida em que se usa, para fins de análise nessa pesquisa, um campo - o campo da modernização agrícola ${ }^{5}$ - na perspectiva de compreender a juventude rural inserida no fenômeno da modernização agrícola no contexto do Sudoeste goiano e a relação de poder existentes nesse campo. O campo da modernização agrícola é um espaço

\footnotetext{
4 Para Bourdieu (1996), espaço social é um campo. "É isso que acredito expressar quando descrevo o espaço social global como um campo, isto é, ao mesmo tempo, como um campo de forças, cuja necessidade se impõe aos agentes que nele se encontram envolvidos [...]." (p. 50) ${ }^{5}$ Campo da modernização agrícola (ver Leal, 2006).
} 


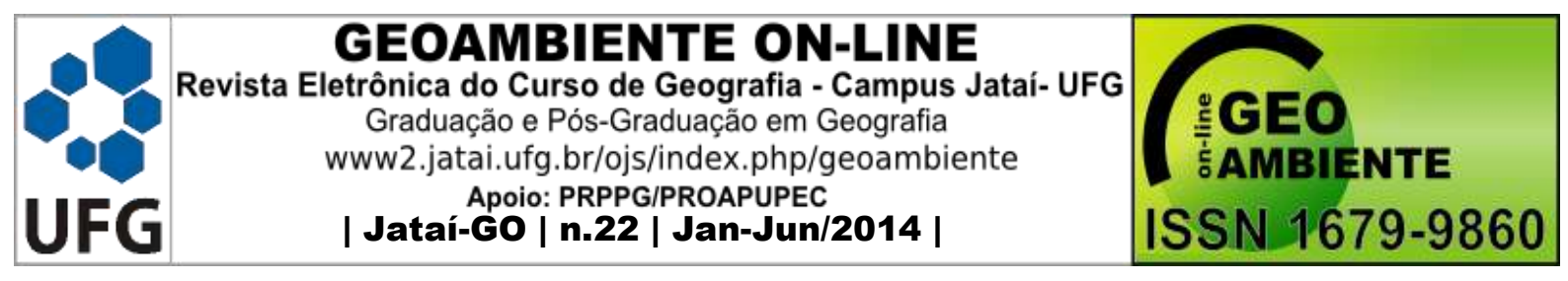

social, como os outros, em que se trata de poder, de capital, de relações de força, de estratégias de manutenção ou de subversão e de interesses.

Segundo Bourdieu, a propriedade definidora de um campo é que todos os agentes que estão engajados nele têm certo número de interesses fundamentais comuns, ou seja, tudo aquilo que está ligado à própria existência do campo, por isso existe uma cumplicidade objetiva subjacente a todos os antagonismos. Pelo simples fato de jogar, de entrar no jogo, a luta pressupõe um acordo entre os antagonismos sobre o que merece ser disputado, e muitas vezes esse fato é escondido por trás da aparência do óbvio, tudo aquilo que constitui o campo, o jogo, os objetos de disputa, todos os pressupostos que são tacitamente aceitos, mesmo sem que se saiba. Os que participam da luta contribuem para a reprodução do jogo colaborando para produzir a crença no valor do que está sendo disputado. Os recém-chegados devem pagar um direito de entrada que consiste no reconhecimento do valor do jogo e dos princípios de seu funcionamento, também chamado de investimento. Eles são levados às estratégias de subversão que, sob pena de exclusão, permanecem dentro de certos limites. As mudanças que ocorrem nos campos colocam em questão os próprios fundamentos do jogo sobre os quais repousa o jogo inteiro. Pelo conhecimento prático dos princípios do jogo, todo o passado está presente em cada ato do jogo. Nele, todas as pessoas "compactuam com a conservação do que é produzido no campo, tendo interesse em conservar e a se conservar conservando" (BOURDIEU, 1983, p. 91-92).

O que está em jogo no campo da modernização agrícola é a mudança na cultura e no habitus do camponês; a passagem de uma economia de subsistência para uma economia eminentemente de mercado, tendo como consequência a manutenção de princípios da modernização conservadora, a proletarização e exclusão do trabalhador rural desse processo, agressões à natureza, mudanças na base técnica de produção, inserção de capital financeiro na agricultura, desenvolvimento desigual e combinado, industrialização da agricultura e formação dos complexos agroindustriais. Segundo Bourdieu, dentro de um campo existem vários agentes que são mobilizados por um interesse comum, por uma idéia única. No campo da modernização agrícola, a moeda comum é o processo de modernização agrícola. Ou seja, nesse campo esses agentes se mobilizam em função dessa moeda comum.

Participam desse jogo diversos agentes coletivos. Para efeito dessa pesquisa, serão delimitados apenas aqueles que são considerados significativos, aqueles que possuem capital suficiente para uma participação na luta concorrencial dentro do campo. De um lado o sistema 


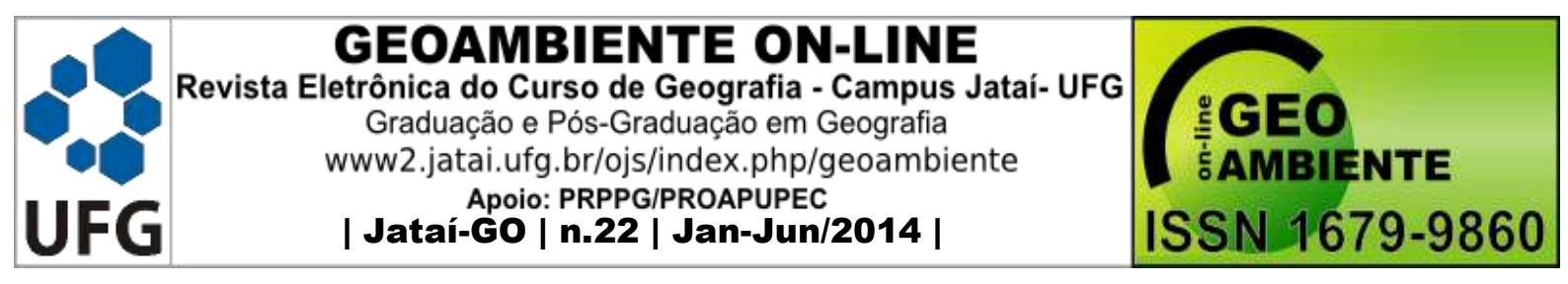

educacional materializado, nesse contexto, nos saberes/práticas educativas transmitidos pelas escolas rurais dos municípios envolvidos na pesquisa. De outro lado os centros especializados materializado, para fins dos resultados dessa pesquisa, pelos saberes/práticas educativas transmitidos pelo projeto "Jovens Rurais".

Sabe-se que educação, ou as chamadas práticas educativas são constitutivas de habitus. Para compreender essas práticas educativas é preciso ampliar a abrangência do campo educacional e adquirir uma nova concepção de educação.

\begin{abstract}
A educação não é uma ação exclusiva do sistema escolar [...] educação é antes de tudo, formação de consciência, aquisição de conhecimento do real, aquisição essa que se faz em sociedade. Os homens educam-se, adquirem consciência, na relação que estabelecem entre si e com a natureza em condições concretas de vida. A educação, portanto, faz-se, não só na prática escolar, mas nas diversas práticas. (LOUREIRO, 1988, p. 20, grifo nosso)
\end{abstract}

Interessa aqui evidenciar a educação elaborada a partir das estratégias de ação utilizadas pelos agentes coletivos no campo da modernização agrícola. São as ações dos agentes coletivos, escolas rurais e centros especializados, que são tomadas aqui como educação. A ação desses agentes coletivos é prenhe de intencionalidade, de significações históricas e sociais, constitutivas e constituintes das relações que eles estabelecem entre si. São nessas ações que são reveladas as suas docências. São nelas que os agentes estabelecem estratégias que asseguram ou não a reprodução e manutenção de seu papel. Elas é que revelam o apoio dado ao avanço da modernização agrícola. É nas ações educativas dos agentes coletivos que é possível perceber se agiram numa perspectiva de reprodução ou de contestação do processo de modernização agrícola no Sudoeste goiano.

\title{
Metodologia
}

A metodologia utilizada para o desenvolvimento da pesquisa foi bibliográfica e documental. Utilizou-se todos os documentos gerados com a execução do projeto "Jovens Rurais", entre eles: projeto, módulos de vivências, apostilas didáticas utilizadas nos módulos, relatórios das vivências, relatórios das visitas técnicas realizadas nos assentamentos, questionários aplicados aos jovens, aos pais dos jovens, e aos membros da comunidade dos assentamentos envolvidos, depoimentos de pais e jovens durante a avaliação de cada uma das vivências, vídeos documentários gerados durante as vivências, cartas, letras de músicas compostas pelos jovens, relatório final do projeto, entre outros documentos. 


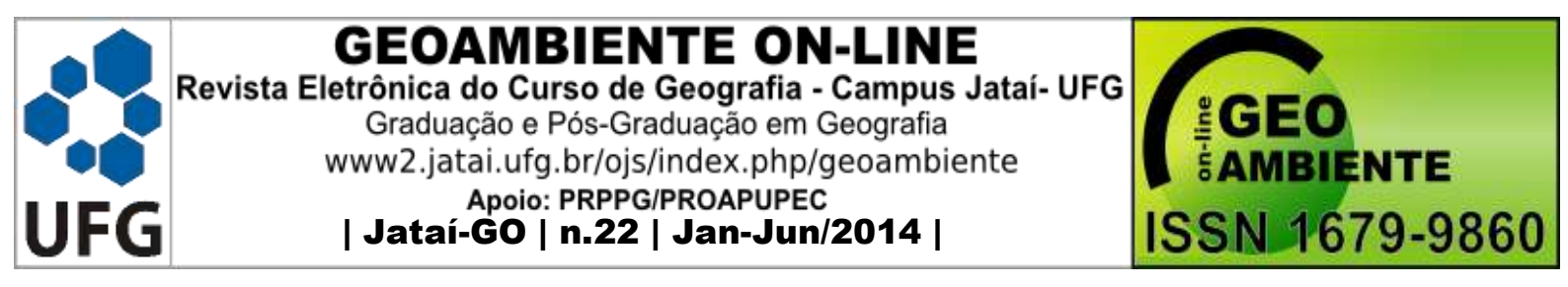

\section{Resultados}

Opta-se, nesse artigo, por apresentar os resultados obtidos com a implementação e execução do projeto "Jovens Rurais" em três dimensões:

Os resultados dos módulos de vivências - Oferta de quatro módulos de vivências universitárias, com 15 dias cada um; Composição de quatro módulos de vivências com temas específicos de acordo com o interesse e a necessidade dos jovens e seus familiares; Oferta de conteúdos teórico-práticos de acordo com os temas tratados; Acompanhamento, da aplicabilidade dos conteúdos tratados, nos lotes e assentamentos dos jovens; Monitoramento das experimentações realizadas pelos jovens participantes do projeto; Orientação e instrumentalização teórico-prática de 60 jovens assentados, com impacto direto em 48 famílias, aproximadamente 240 pessoas; Multiplicação do aprendizado, por parte dos jovens, nos seus assentamentos de origem, com impacto indireto em 170 famílias, aproximadamente 850 pessoas.

Os resultados técnicos - Compreensão, por parte das famílias, da economia doméstica; Diversificação e aumento da produção e produtividade; Aumento da renda familiar; Diversificação de alimentos para o consumo diário das famílias envolvidas no projeto; Redução dos custos de manutenção do lote e da família; Incremento da criação e do manejo de animais para corte, leite e postura; Articulação para a comercialização da produção dos assentamentos; Formação de multiplicadores dos conhecimentos técnico-científicos tratados durante os módulos de vivência; Uso e aproveitamento de resíduos para a adubação e proteção do solo; Aproveitamento de resíduos orgânicos; Integração de cultivos; Uso de materiais alternativos para construções diversas; Reuso de materiais para a produção de utensílios e artesanatos.

Os resultados sociais - Maior envolvimento dos jovens nas atividades diárias do assentamento; Redução do interesse de migrar para as cidades e abandonar as áreas rurais; Interesse em seus lotes e áreas rurais; Envolvimento nas reuniões das Associações dos assentamentos; Progresso na comunicação com outras pessoas, dentro e fora do assentamento; Melhora da autoestima; Atuação como agentes multiplicadores de conhecimentos nos assentamentos de origem; Melhoria da qualidade de vida; Maior envolvimento com as atividades e a vida escolar; Articulação entre os jovens, dentro do próprio assentamento e entre assentamentos; Organização de eventos sociais como: torneios esportivos, reuniões, 


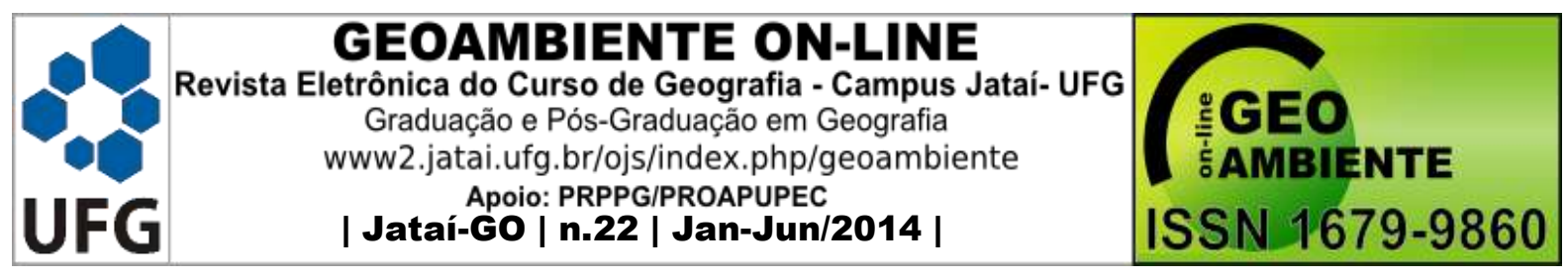

festejos e construção de uma biblioteca; Interesse na formação continuada, sobretudo, em fazer curso superior.

\section{Discussões}

As estratégias ou práticas educativas desenvolvidas no campo da modernização agrícola pelos dois agentes coletivos analisados, escolas rurais e centro especializado projeto "Jovens Rurais", cada um a seu modo, procuram instrumentalizar os jovens com moeda suficiente para entrar numa luta concorrencial, numa disputa por um modelo de desenvolvimento agrícola.

Segundo Leal (2008), as escolas rurais, da forma como foram historicamente constituídas nessa região, assume uma dimensão oca na medida em que é esvaziada de preocupações que operem transformações benéficas reais, assumindo um modelo utilizado para criar necessidades de consumo dos produtos oriundos do campo da modernização agrícola, considerando aí inclusive produtos culturais e ideológicos. Ou seja, as práticas educativas presentes no campo se tornaram uma educação que não interage com o estudante rural enquanto tal.

De acordo com Pessoa, "podemos dizer que não existe escola rural, mas que existe no campo apenas um tosco arremedo da escola urbana" e que "a rigor não existe educação rural; existem fragmentos de educação escolar urbana introduzido no meio rural. A própria educação escolar é, em si mesma, uma instituição emissária do poder que se concentra na cidade e, de lá, subordina a vida e o homem do campo" (PESSOA, 1997, p. 154).

Para Brandão (1993), a educação pode existir livre e entre todos, pode ser uma das maneiras que as pessoas criam para tornar comum aquilo que é comunitário, como bem, como trabalho ou como vida. Ela é, entre outras coisas, uma fração do modo de vida dos grupos sociais que a criam e recriam, entre tantas outras invenções de sua cultura, em sua sociedade. A educação existe onde há a escola e por toda parte em que há redes e estruturas sociais de transferência de saber de uma geração a outra. Ela existe sob diferentes formas e é praticada em diferentes situações. Vista em seu vôo mais livre, a educação aparece como relações entre pessoas e intenções de ensinar-e-aprender.

Ninguém escapa da educação. Em casa, na rua, na igreja ou na escola, de um modo ou de muitos todos nós envolvemos pedaços da vida com ela: para aprender, para 


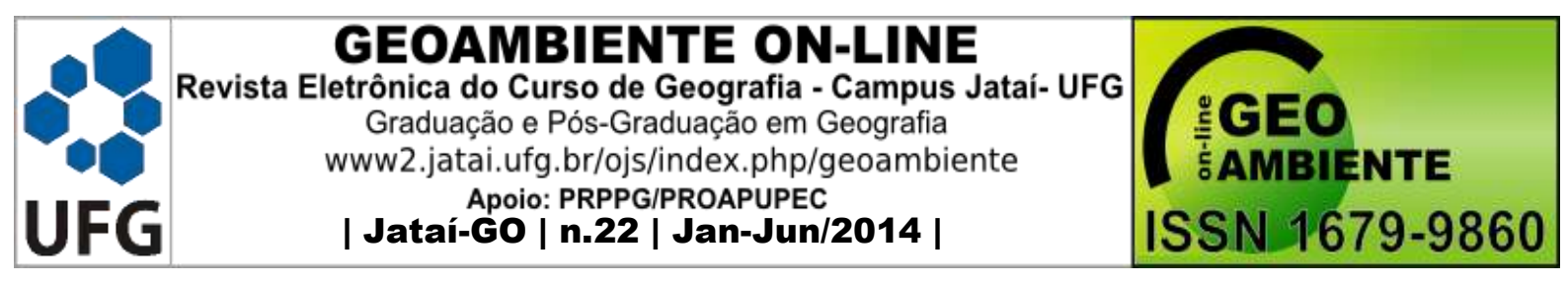

ensinar, para aprender-ensinar. Para saber, para fazer, para ser ou para conviver. Todos os dias misturamos a vida com a educação. (BRANDÃO, 1993, p. 7)

Para o autor, a educação é uma prática social cujo fim é o desenvolvimento do que na pessoa humana pode ser aprendido entre os tipos de saber existentes em uma cultura, para a formação de tipos de sujeitos, de acordo com as necessidades e exigências de sua sociedade, em um momento da história de seu próprio desenvolvimento. Como outras práticas sociais constitutivas, a educação atua sobre a vida e o crescimento da sociedade em dois sentidos: no desenvolvimento de suas forças produtivas; e no desenvolvimento de seus valores culturais.

Brandão (1990) ainda enfatiza que a educação existe na história e nas sociedades do homem; não é exterior a ele e, em todos os sentidos, é uma construção social do homem. Ela existe em formações sociais concretas, faz parte de suas estruturas de saber-e-poder e participa de inúmeros processos e inúmeras situações coletivas que têm a ver com questões de reprodução do saber e de manutenção do poder. A educação é uma instituição social. Ela é parte do aparato de que as classes e grupos de controle do poder lançam mão para realizar, dentro do tipo de sociedade que impõem, os seus objetivos e interesses exclusivos sobre a economia, a política e também sobre a cultura.

Nessa perspectiva, parece clara a intencionalidade das práticas educativas desencadeadas pelas escolas rurais dessa região. Funcionam como estratégias para conservar o modelo de desenvolvimento agrícola existente no campo da modernização agrícola.

O projeto "Jovens Rurais" desenvolveu práticas educativas, desencadeando os resultados apontados acima, que poderiam ser chamadas de contra estratégias ou estratégias contra hegemônicas, pois procurou instrumentalizar os jovens com saberes que possibilitaram um aumento de capital simbólico capaz de colocá-los na luta concorrencial no campo da modernização agrícola.

As estratégias funcionam como investimentos dentro do campo, pois são elas que possibilitam o aumento de capital, segundo a oportunidade que o seu detentor tiver de operar as aplicações mais rentáveis. A razão desse investimento é a acumulação de formas de capital que garantam a dominação no campo, que se apresenta como um espaço de forças. Os agentes em oposição dentro desse campo podem optar por estratégias de conservação ou subversão, de acordo com o seu interesse no campo.

A reprodução dos agentes sociais no campo explica-se pelas múltiplas estratégias que eles mobilizam para a conservação ou a apropriação de capital. Com isso, eles procuram 


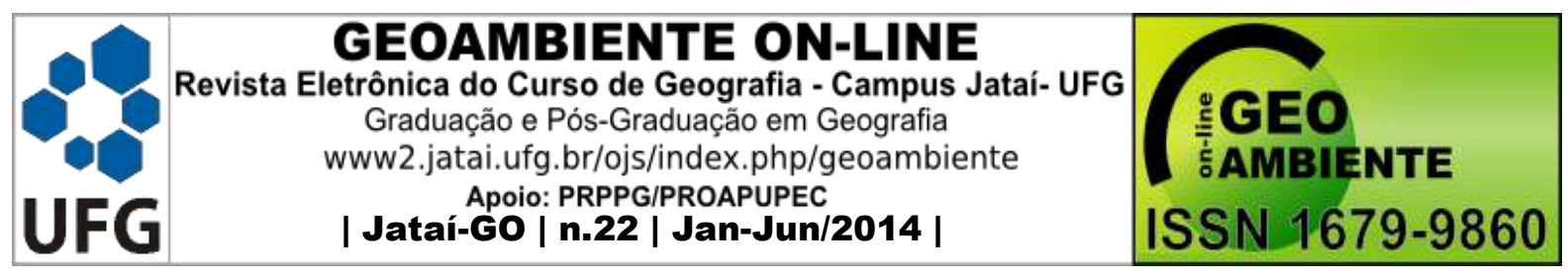

sempre manter ou melhorar sua posição social dentro do campo. Os mecanismos de conservação da ordem social predominam em razão da importância das estratégias de reprodução.

\begin{abstract}
Uma das questões fundamentais sobre o mundo social é saber por que e como o mundo dura, persevera no ser e se perpetua a ordem social, isto é, o conjunto das relações de ordem que o constituem. [...] Pode-se estabelecer uma espécie de quadro das grandes classes de estratégia de reprodução [...] que se encontram em todas as sociedades, mas com pesos diferentes [...] e sob formas que variam segundo a natureza do capital que deve ser transmitido e o estado dos mecanismos de reprodução disponíveis. (BONNEWTZ, 2003, p. 67)
\end{abstract}

Essas estratégias de reprodução podem ser de diferentes ordens, como as de investimento biológico, de sucessão, de investimento econômico, de investimento simbólico e de investimento educativo. As estratégias educativas visam reproduzir agentes sociais capazes de receber e transmitir a herança do grupo. A eficácia das estratégias de reprodução depende dos instrumentos de reprodução postos à disposição dos agentes.

As diferentes estratégias que os agentes sociais desenvolvem no interior dos diversos campos sociais encontram a sua explicação em função das posições que esses agentes ocupam na polarização. Aqueles que monopolizam o capital específico ${ }^{6}$ de um determinado campo estão inclinados a tomadas de posições em defesa dos princípios de estruturação do campo. Adotam em suas condutas estratégias de conservação da posição dominante que nele ocupam. Por outro lado, os que possuem menos volume de capital exigido pelo campo tendem a tomar posições de contestação em relação à estruturação das relações de poder e, em decorrência disso, desenvolvem estratégias de transformação. Essa situação cria, segundo Bourdieu (1983), uma ruptura crítica frequentemente ligada à crise, o que faz com que os dominantes saiam de seu silêncio impondo a produção do discurso defensivo visando restaurar o equivalente da adesão silenciosa.

Para Bourdieu, todo ator social que age no interior de um campo específico procura ajustar o seu esquema de pensamento, percepção e ação às exigências objetivas daquele espaço social. Os campos sociais não podem funcionar a não ser que existam agentes que realizam investimentos no seu interior, engajando seus recursos disponíveis e participando de suas disputas fundamentais, contribuindo assim para a reativação das lutas que neles se

\footnotetext{
${ }^{6}$ Capital específico é o capital que vale em relação a um certo tipo de campo, dentro dos limites desse campo, e que só é convertido em outra espécie de capital sob certas condições.
} 


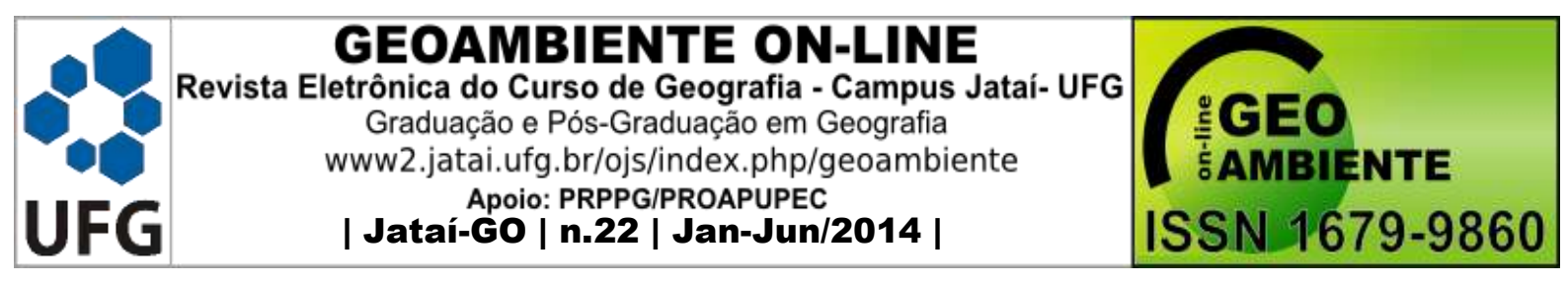

desenvolvem. O motor da ação para esse ator social repousa na relação entre o habitus e o campo. Em decorrência dessa relação, o habitus contribui para a preservação do campo, dos seus princípios de funcionamento e de organização, bem como para a reatualização dos antagonismos nele existentes.

Para o autor, toda vez que se estuda um novo campo, descobrem-se propriedades especificas, próprias a um campo particular, ao mesmo tempo em que se faz avançar o conhecimento dos mecanismos universais dos campos que se especificam em função de variáveis secundárias. Sabe-se que em cada campo se encontrará uma luta, da qual se deve, cada vez, procurar as formas específicas, entre o novo que está entrando, e que tenta forçar o direito de entrada, e o dominante que tenta defender o monopólio e excluir a concorrência. Uma das características importantes do campo é que ele se constitui como um espaço em que se trava, entre os agentes, uma luta concorrencial decorrente de relações de poder existentes em seu interior. Essas relações derivam da distribuição desigual da espécie de capital dominante em cada um dos diversos campos sociais, que são hierarquizados em polos distintos.

\section{Algumas considerações}

Nos termos de Bourdieu, temos no campo da modernização agrícola a formação de um novo habitus. Um habitus agromodernizado (estrutura estruturada) e agromodernizador (estrutura estruturante). Em sua dimensão agromodernizada, as pessoas introjetam e assimilam o modo como as coisas são dentro desse campo; em sua dimensão agromodernizadora, ele passa a ditar o comportamento das pessoas dentro do campo, ou fazer com que elas reproduzam esse habitus. O campo da modernização agrícola dita os novos habitus, e cada um dos agentes passa a reproduzi-lo, ou seja, já estão estabelecidos para cada agente os seus papéis dentro do campo: trazer, manter e reproduzir a lógica do campo.

Essa formação de novos habitus foi possível em função das estratégias de ação adotadas pelos agentes coletivos, especialmente as escolas rurais, no campo da modernização agrícola. Entender essas estratégias como práticas educativas é possível, pois, como diz Brandão (1993), não há uma forma única nem um único modelo de educação. Ela existe em mundos diversos e de diferentes maneiras. Ela existe em cada categoria de sujeitos de um povo, em cada povo, e entre povos que se encontram, e existe entre povos que submetem e dominam outros povos, usando a educação como um recurso a mais de sua dominação. 


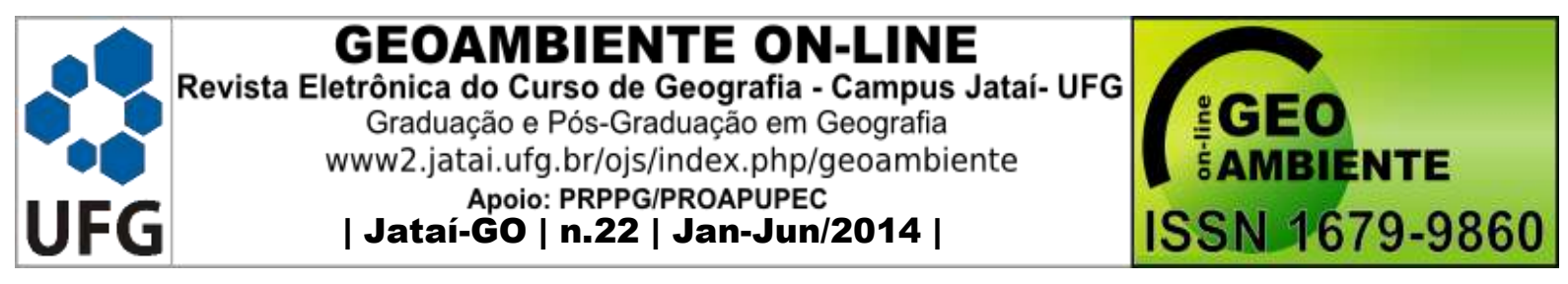

Em todos os tipos de sociedades, a educação é um dos mais eficazes instrumentos de controle social, quer apareça difusa e não formalizada, quer apareça formalizada. Ela é uma das práticas sociais usadas, com frequência, para controle de ideias e condutas. Os conteúdos dessa educação conduzem a mensagens que legitimam a ordem social. Assim, ao ensinar alguma coisa, ensinam-se os valores de uma ordem social que se impõe ser reconhecida como legítima e necessária, ao mesmo tempo em que se inculcam conhecimentos e habilidades tidas como necessárias e legítimas, para que as pessoas educadas preservem e reconstruam a ordem econômica, política e simbólica da sociedade.

Para Brandão (1990), todo o exercício de educação tem uma dimensão instrumentalizadora. Ela responde a necessidades gerais e especializadas das pessoas, por isso os controladores da educação definem toda a sua prática e determinam o que ela deve ser. Assim, nada é gratuito e nem puramente educativo na educação. Se, em um nível mais visível, ela parece ser pensada e exercida de modo a produzir benefícios diretos ou indiretos para todas as pessoas; em outro nível, o que se esconde sob as realizações do primeiro, ela se soma a tudo que serve para controlar o pensamento, as iniciativas, enfim, a vida individual e coletiva de todos os sujeitos de algum modo envolvidos em suas tramas.

Os dados desta pesquisa indicam que o modelo de educação presente nesse campo assume essa dimensão instrumentalizadora, pois se constitui esvaziado de preocupações que possam operar transformações benéficas a todas as pessoas, assumindo um modelo que é utilizado para criar necessidades de consumo dos produtos industrializados na produção agropecuária, sendo que, com esse consumo, dá-se o aumento da produção e o êxito do trabalho educativo.

Todas essas práticas educativas se corporificam no campo da modernização agrícola, tornando-se uma educação que busca atender a determinadas finalidades. Brandão (1990) reforça que a educação pode ter diferentes finalidades e, às vezes, ter usos escusos. Pode ser usada para professar idéias que interessem apenas a determinada parcela da sociedade. A educação existe no imaginário das pessoas e na ideologia dos grupos sociais, e ali sempre se espera, de dentro, ou sempre se diz, de fora, que sua missão é transformar sujeitos e mundos em alguma coisa melhor, de acordo com as imagens que se têm de uns e outros. Mas, na prática, a mesma educação que ensina pode deseducar, e pode-se correr o risco de fazer o contrário do que se pensa que faz, ou do que se inventa que pode fazer. 


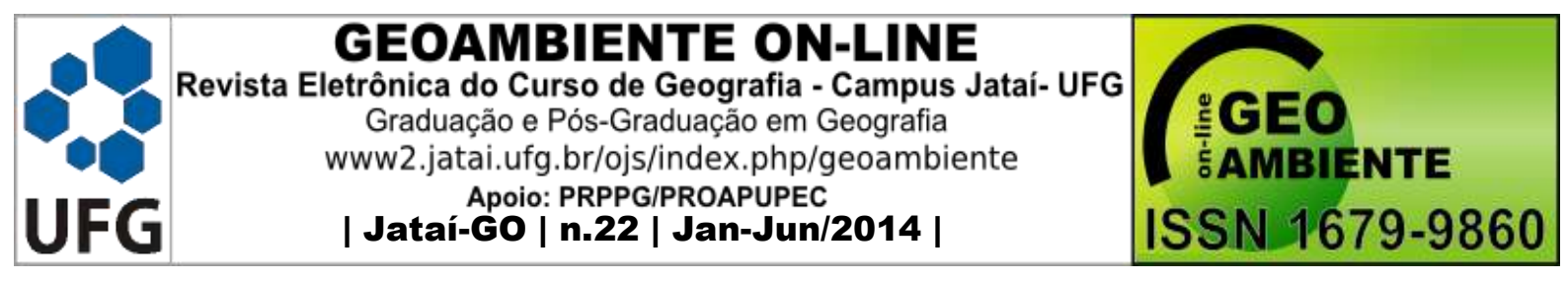

A inversão, ao menos parcial, dessas situações pode estar diretamente ligada à constituição de novas práticas educativas dos sujeitos históricos que compõem a região estudada, assumindo um (re)redirecionamento desse modelo de desenvolvimento agrícola. Essas práticas educativas foram percebidas na execução do projeto "Jovens Rurais" e são capazes da geração de novos habitus. Novos habitus podem ser constitutivos de condutas que levem a juventude rural deterem capital suficiente para entrar numa luta concorrencial dentro do campo da modernização agrícola. Como consequência dessa luta pode-se ter a inversão, ao menos parcial, desse modelo de desenvolvimento exógeno e excludente historicamente constituído nessa região.

O habitus permite aos indivíduos orientarem-se em um espaço social e adotarem práticas que estão de acordo com sua vinculação social. Ele torna possível ao indivíduo a elaboração de estratégias antecipadoras que são guiadas por esquemas inconscientes que resultam do trabalho de educação e de socialização ao qual o indivíduo está submetido; é também a incorporação da memória coletiva. Cada pessoa, por seus gestos e suas posturas, revela o habitus profundo que o habita, sem se dar conta e sem que os outros tenham necessariamente consciência disso. Pelo habitus, as características sociais são de certa forma naturalizadas: o que parece e o que é vivido como natural depende de um habitus. Essa naturalização do social é um dos mecanismos que garantem mais eficazmente a perenidade do habitus.

\section{Referências}

BONNEWITZ, Patrice. Primeiras lições sobre a sociologia de P. Bourdieu. Petrópolis: Vozes, 2003.

BOURDIEU, Pierre. O poder simbólico. Rio de Janeiro: Bertrand Brasil, 1998.

Questões de sociologia. Rio de Janeiro: Marco Zero, 1983.

. Razões práticas: sobre a teoria da ação. Campinas: Papirus, 1996.

BRANDÃO, Carlos Rodrigues. O que é educação. São Paulo: Brasiliense, 1993. 


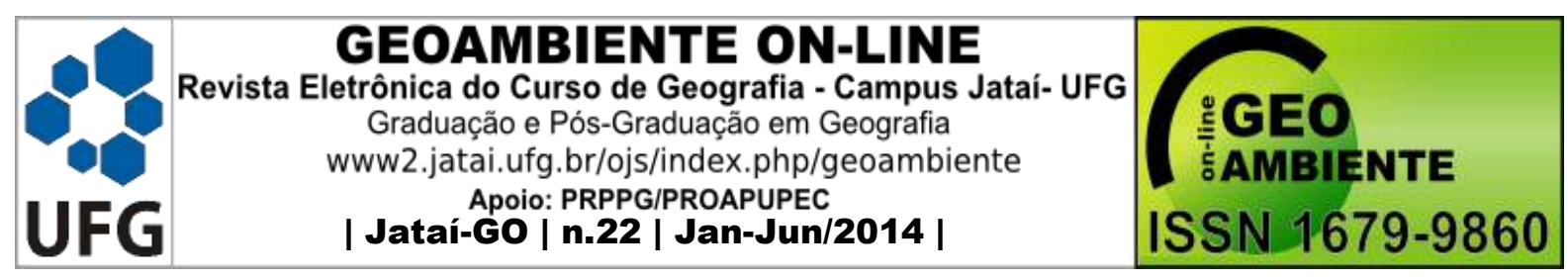

Pensar a prática: escritos de viagem e estudos sobre a educação. São Paulo: Loyola, 1990.

CUCHE, Denys. A noção de cultura nas ciências sociais. Bauru: EDUSC, 2002.

LEAL, Cátia Regina A. A.. Arapuca armada: ação coletiva e práticas educativas na modernização agrícola do Sudoeste goiano. Goiânia, 2006. 256f. Tese (Doutorado em Educação) - Faculdade de Educação, Universidade Federal de Goiás.

LEAL, Cátia Regina A. A. et.al. Educação rural jataiense: sentidos e significados. In: XVII Simpósio de Estudos e Pesquisa da Faculdade de Educação/UFG, Goiânia - GO, mai. 2008 .

LOUREIRO, Walderês Nunes. O aspecto educativo na prática política. Goiânia: Editora da UFG, 1988.

MARTINS, Carlos Benedito. Estrutura e ação: a teoria da prática em Bourdieu. Educação \& Sociedade. Campinas, n. 27, p. 33-46, set. 1987.

ORTIZ, Renato. A sociologia de Pierre Bourdieu. São Paulo: Olho d’Água, 2003.

PESSOA, Jadir de Morais. Artigo 28 sem rodeios: a educação rural na nova LDB. In: Fragmentos de cultura. Goiânia, v. 28, n. 7, 1997, p. 149-158. 